\title{
Cavernous Sinus Epidermoid Cyst Removal through a No-Keyhole Pterional Craniotomy: Operative Video and Technical Nuances
}

\author{
Carlos Candanedo $^{1 \oplus}$ Samuel Moscovici ${ }^{1}{ }^{\circledR}$ Sergey Spektor ${ }^{1}{ }^{\circledR}$ \\ ${ }^{1}$ Department of Neurosurgery, Hadassah-Hebrew University Medical \\ Center, Jerusalem, Israel \\ J Neurol Surg B Skull Base 2022;83(suppl S3):e623-e624. \\ Address for correspondence Carlos Candanedo, MD, Department of \\ Neurosurgery, Hadassah-Hebrew University Medical Center, P.O. Box \\ 12000 , Jerusalem 91120 , Israel \\ (e-mail: ccandanedomd@hotmail.com).
}

\begin{abstract}
Keywords

- anterior clinoidectomy

- cavernous sinus

- epidermoid cyst

- oculomotor nerve

- operative video

- posterior petroclinoid ligament

- pterional craniotomy
\end{abstract}

Intracranial epidermoid cysts are considered benign tumors with good general prognosis. However, their radical removal may be associated with certain morbidity, especially when the capsule is attached to neurovascular structures. Epidermoid cysts located in the cavernous sinus are very rare. We present an operative video of a 22-yearold female patient, who suffered a right-sided headache for 5 years. The video demonstrates main steps and surgical nuances of resection of a right interdural cavernous sinus epidermoid cyst, measuring $22 \times 19 \times 21 \mathrm{~mm}$ (4.3 cc) (-Fig. 1A). On initial physical examination, the patient had a right partial third nerve palsy (mild ptosis with minimal diplopia), without any other cranial nerve deficit. A right no-keyhole pterional craniotomy was performed, followed by extradural anterior clinoidectomy and peeling of the outer dural layer of the lateral wall of the cavernous sinus. The dura matter was also detached from the distal carotid dural ring, which was exposed by the clinoidectomy (-Fig. 2A). This maneuver provided excellent exposure of the interdural epidermoid cyst, which severely compressed the oculomotor nerve against the posterior petroclinoid dural fold ( - Fig. 2B). Gross total resection of the epidermoid cyst was achieved (- Fig. 1B and C). The patient developed a transient worsening of the third nerve palsy, which recovered completely 3 months after the surgery. Postoperative magnetic resonance imaging revealed no signs of residual tumor. The link to the video can be found at: https://youtu.be/pobhYb5ZNig.

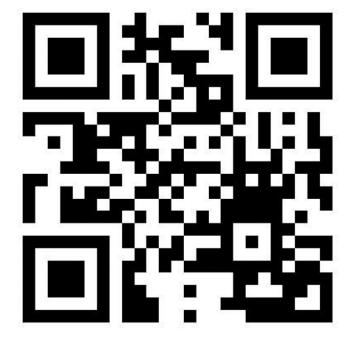

received

March 28, 2020

accepted

November 3, 2020

published online

May 3, 2021

www.thieme.com/skullbasevideos

www.thieme.com/jnlsbvideos

DOI https://doi.org/ 10.1055/s-0041-1727118. ISSN 2193-6331.

\footnotetext{
(C) 2021. The Author(s).

This is an open access article published by Thieme under the terms of the Creative Commons Attribution-NonDerivative-NonCommercial-License, permitting copying and reproduction so long as the original work is given appropriate credit. Contents may not be used for commercial purposes, or adapted, remixed, transformed or built upon. (https://creativecommons.org/ licenses/by-nc-nd/4.0/) Georg Thieme Verlag KG, Rüdigerstraße 14, 70469 Stuttgart, Germany
} 


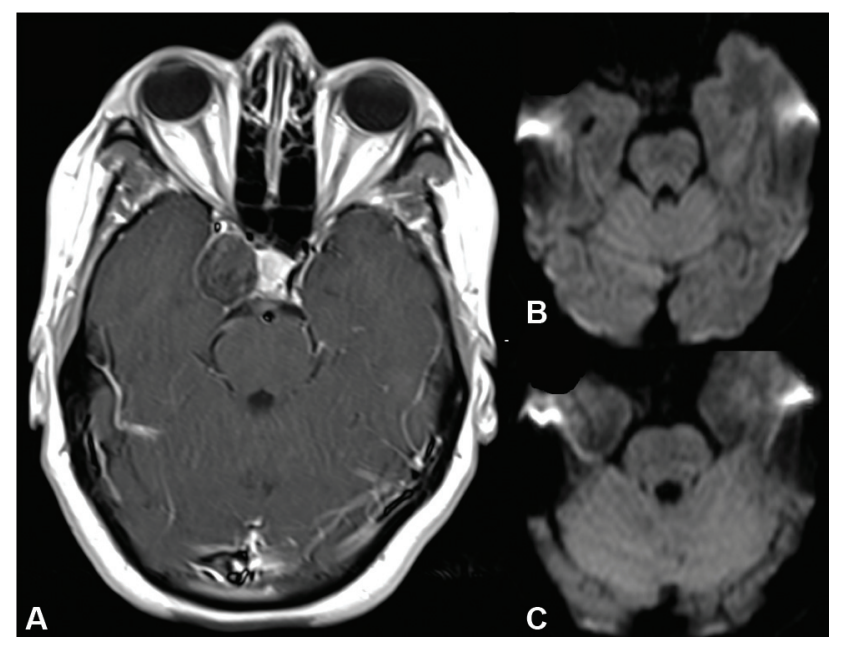

Fig. 1 (A) Preoperative axial T1 gadolinium-enhanced magnetic resonance imaging showing the right cavernous sinus epidermoid cyst. (B, C) Two different axial views on postoperative diffusion weighted imaging without any sign of restricted diffusion, meaning no signs of tumor residual.

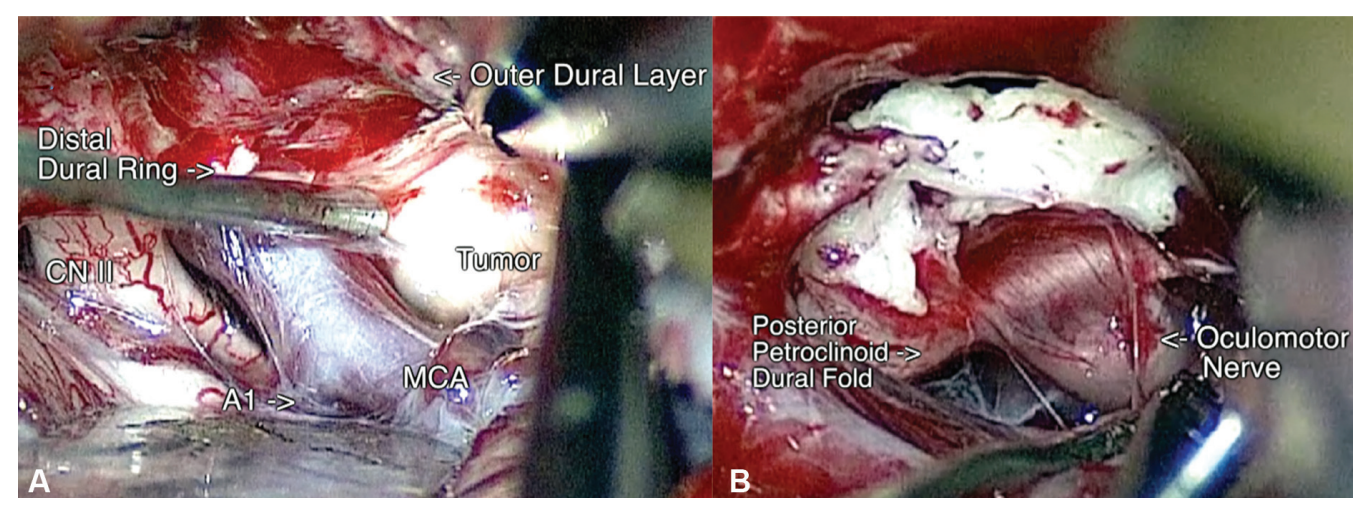

Fig. 2 Intraoperative imaging in the right pterional approach showing (A) neurovascular structures including the optic nerve (CN II), middle cerebral artery, first segment of the anterior cerebral artery (A1) and the distal dural ring exposed thanks to the previously performed extradural anterior clinoidectomy, and (B) severe compression to the oculomotor nerve from the tumor against the posterior petroclinoid dural fold.

\section{Conflict of Interest}

None declared. 